\title{
Neuroprotective Ferulic Acid (FA)-Glycol Chitosan (GC) Nanoparticles for Functional Restoration of Traumatically Injured Spinal Cord
}

\author{
Wei $\mathrm{Wu}^{\# 1}$, Seung-Young Lee ${ }^{\# 2}$, Xiangbing $\mathrm{Wu}^{3}$, Jacqueline Y. Tyler ${ }^{2}$, He Wang $^{2}$, Zheng \\ Ouyang $^{2}$, Kinam Park ${ }^{2}$, Xiao-Ming X ${ }^{1,3,}{ }^{*}$, and Ji-Xin Cheng ${ }^{2,4,{ }^{*}}$ \\ ${ }^{1}$ Department of Neurobiology, Shanghai Jiaotong University School of Medicine, Shanghai, P.R. \\ China \\ 2 Weldon School of Biomedical Engineering, Purdue University, West Lafayette, IN 47907 \\ ${ }^{3}$ Spinal Cord and Brain Injury Research Group, Stark Neurosciences Research Institute, \\ Department of Neurological Surgery, Department of Anatomy and Cell Biology, Goldman and \\ Campbell Brain and Spine, Indiana University School of Medicine, Indianapolis, IN 46202 \\ ${ }^{4}$ Department of Chemistry, Purdue University, West Lafayette, IN 47907 \\ \# These authors contributed equally to this work.
}

\begin{abstract}
An urgent unmet need exists for early-stage treatment of spinal cord injury (SCI). Currently methylprednisolone is the only therapeutic agent used in clinics, for which the efficacy is controversial and the side effect is well-known. We demonstrated functional restoration of injured spinal cord by self-assembled nanoparticles composed of ferulic acid modified glycol chitosan (FA-GC). Chitosan and ferulic acid are strong neuroprotective agents but their systemic delivery is difficult. Our data has shown a prolonged circulation time of the FA-GC nanoparticles allowing for effective delivery of both chitosan and ferulic acid to the injured site. Furthermore, the nanoparticles were found both in the gray matter and white matter. The in vitro tests demonstrated that nanoparticles protected primary neurons from glutamate-induced excitotoxicity. Using a spinal cord contusion injury model, significant recovery in locomotor function was observed in rats that were intravenously administered nanoparticles at $2 \mathrm{~h}$ post injury, as compared to nonimprovement by methylprednisolone administration. Histological analysis revealed that FA-GC treatment significantly preserved axons and myelin and also reduced cavity volume, astrogliosis, and inflammatory response at the lesion site. No obvious adverse effects of nanoparticles to other organs were found. The restorative effect of FA-GC presents a promising potential for treating human SCIs.
\end{abstract}

C) 2013 Published by Elsevier Ltd

*Corresponding authors: xu26@iupui.edu,jcheng@purdue.edu.

Publisher's Disclaimer: This is a PDF file of an unedited manuscript that has been accepted for publication. As a service to our customers we are providing this early version of the manuscript. The manuscript will undergo copyediting, typesetting, and review of the resulting proof before it is published in its final citable form. Please note that during the production process errors may be discovered which could affect the content, and all legal disclaimers that apply to the journal pertain. 


\section{Introduction}

Few effective treatments exist for traumatic spinal cord injury (SCI) [1, 2]. Difficulties in therapeutic development derived from complex temporospatial profiles of the two pathological phases of SCI: a primary mechanical injury and a subsequent secondary damage instigated by the initial trauma [3]. The primary injury, which is inclined to insult gray matter, results in immediate ischemia and energy failure by disruption of blood vessels and cell membranes, while the secondary injury is mediated by multiple neurodegenerative processes that exacerbate the primary damage [4-6]. Therefore, early repair of SCI by neuroprotective agents is critical to prevent not only temporal progression, but also spatial spread of the primary injury. Currently, methylprednisolone (MP) is the only therapeutic agent used clinically for SCI, for which its efficacy and safety are controversial [7-10].

To date, neuroprotective medicine using various biomaterials has been proposed for early SCI treatment [11-13]. The implantation of methylprednisolone (MP)-loaded poly(lactic-coglycolic acid) (PLGA) nanoparticles embedded in an agarose hydrogel in an injured spinal cord allowed to sustainably and spatially release MP, resulting in decreased inflammation and lesion volume after a contusive SCI [14]. The neuroactive pentapeptide epitope, selfassembled into cylindrical nanofibers after injection into an injured spinal cord, reduced astrogliosis and cell death, and increased the number of oligodendroglia at the injury site [15]. Also, the local injection of glial cell line-derived neurotrophic factor encapsulated in PLGA nanoparticles into the injured spinal cord after contusion in rats preserved neuronal fibers and led to increase in locomotor function [16]. Furthermore, synthetic nano-sized polymers themselves have been recently recognized as a new class of neuroprotective agents for early SCI therapy $[17,18]$. Local application of a high-concentration of poly(ethylene glycol) protected spinal cord tissue from reactive oxygen species and lipid peroxidationinduced damage, by repair of nerve membranes that led to restoration of compound action potential conduction and locomotor function after compression/contusion injury in adult guinea pigs [19, 20]. Poloxamer 188 (P188) micelles rescued neuron cells from glutamate toxicity [21], and also improved functional outcome from SCI through aortic cross-clamping by intercalating into neuronal membranes [22]. Self-assembled monomethoxy poly(ethylene glycol)-poly(D,L-lactic acid) di-block copolymer micelles not only repaired injured axonal membranes, but also reduced calcium influx into axons, resulting in significant improvement of locomotor function after traumatic SCI in adult rats [23]. Although SCI treatment using the synthetic nano-sized polymers has demonstrated some therapeutic effects, the polymers had to be administrated within a short period of time ( $15 \mathrm{~min})$ after the injury, or even before the injury, to become effective. Such time windows are not clinically relevant.

Here, we report a neuroprotective nanomedicine composed of ferulic acid modified glycol chitosan, represented by the acronym FA-GC, that can restore locomotor function following traumatic SCI within a clinically-relevant therapeutic time window. Ferulic acid (FA) and glycol chitosan (GC) are both recognized as natural neuroprotective compounds [24, 25]. FA, which is abundant in cell wall of commelinid plants such as rice, wheat, or in seeds of coffee, apple, peanut, etc., has been shown to protect neurons after cerebral ischemic injury through its anti-inflammatory, anti-oxidative, and anti-excitotoxicity effects [26-28]. The phenolic hydroxyl group in FA can absorb a hydrogen atom to form a phenoxy radical, 
protecting cells from oxidative stress [29, 30]. Chitosan, which is produced mainly from the exoskeleton of crustaceans (e.g. crabs and shrimps), has proven neuroprotective effects on membrane sealing, anti-inflammatory, anti-oxidative, and anti-excitotoxicity effects as well [31-34]. It was shown that primary amines, abundant in chitosan, may play a key role in neuroprotection $[35,36]$. However, due to poor solubility of chitosan in an aqueous solution with neutral $\mathrm{pH}$, we employed a water-soluble, glycol chitosan (GC) maintaining its neuroprotective effect derived from the primary amines in original chitosan [37].

By chemically conjugating FA to GC to form hydrophobically self-assembled nanoparticles composed of a hydrophobic FA core and a hydrophilic GC shell, our scheme significantly extends their half-life in the blood stream so that the neuroprotective effect is sufficiently realized. We determined the therapeutic effect of FA-GC nanoparticles via the Basso, Beattie and Bresnahan locomotor scale after spinal cord contusion in rats [38]. We characterized the distribution of FA-GC nanoparticles by fluorescence and stimulated Raman scattering microscopy imaging at cellular levels. We further performed histological analyses including astrogliosis, macrophage/microglia reaction, and spared axon and myelin analyses. Finally, we assessed in vivo toxicity of FA-GC nanoparticles via hematological and histological analyses.

\section{Materials and Methods}

Glycol chitosan $(\mathrm{GC})\left(\mathrm{M}_{\mathrm{w}}=250 \mathrm{KDa}\right.$; degree of deacetylation = 82.7\%), trans-ferulic acid (FA), N-hydroxysuccinimide (NHS), 1-ethyl-3-(3-dimethylaminopropyl)-carbodiimide hydrochloride (EDC), HEPES sodium salt, poly-L-lysine, cytosine- $\beta$-D-arabinofuranoside, Hoechst 33342, propidium iodide (PI), and glutamate were purchased from Sigma (St. Louis, MO). The monoreactive hydroxysuccinimide ester of Cy5.5 was from Amersham Biosciences (Piscataway, NJ). Anhydrous dimethyl sulfoxide (DMSO) and methanol were purchased from Merck (Darmstadt, Germany). All other chemicals were of analytical grade, and used without further purification.

\section{Synthesis and characterization of ferulic acid (FA)-glycol chitosan (GC) nanoparticles}

Ferulic acid (FA) was conjugated to glycol chitosan (GC) at three different molar ratios of FA to GC (45, 90, and 180). Glycol chitosan $(0.1 \mathrm{~g}, 4 \mu \mathrm{M})$ was dissolved in HEPES buffer $(\mathrm{pH} 7.5)(20 \mathrm{ml})$, followed by dilution with DMSO $(10 \mathrm{ml})$, and the different amounts of ferulic acid acid (3.5-14 mg, 180-720 $\mu \mathrm{M})$ was added Chemical modification was initiated by adding equal amounts (1.5-fold molar excess of ferulic acid) of EDC and NHS. The resulting solutions were stirred for 1 day at room temperature, dialyzed (molecular cutoff $=$ $12 \mathrm{KDa})$ for 3 days against excess water/methanol $(1: 4 \mathrm{v} / \mathrm{v})$, followed by dialysis against distill water, and products were lyophilized to obtain glycol chitosan conjugates with different molar ratio of ferulic acid. Synthesized conjugates were chemically analyzed using ${ }^{1} \mathrm{H}$ NMR spectroscopy (ARX-400, Bruker, Germany) and FT-IR (Nicolet NEXUS 470, Thermo). The degree of substitution, defined as the number of ferulic acid groups per one sugar residues of glycol chitosan, was determined by UV absorbance at $316 \mathrm{~nm}$.

FA-GC conjugates were dispersed in PBS buffer ( $\mathrm{pH}$ 7.4) by sonication to produce homogeneously nano-sized FA-GC nanoparticles. The sizes of FA-GC nanoparticles were 
determined using dynamic light scattering (DLS) (DLS, 90Plus, Brookhaven Instruments Co., NY) at $633 \mathrm{~nm}$ and $25^{\circ} \mathrm{C}$. The morphologies of FA-GC nanoparticles in distilled water were observed using transmission electron microscopy (TEM) (CM 200 electron microscope, Philips). Nanoparticles deposited on the grid were negatively stained with $2 \mathrm{wt}$ $\%$ uranyl acetate solution. The surface charges of FA-GC nanoparticles in distilled water were determined using a zeta potential analyzer (ZetaPlus, Brookhaven Instruments Co., NY).

\section{Cy5.5-labeled FA-GC nanoparticles}

To label Cy5.5 to FA-GC polymer or GC, 1 wt \% hydroxysuccinimide ester of Cy5.5 was dissolved in DMSO and mixed with FA-GC or GC solution. The reaction was performed at room temperature in the dark for $6 \mathrm{~h}$. Byproducts and unreacted Cy5.5 molecules were removed over a period of two days by dialysis (molecular weight $=12 \mathrm{KDa}$ ) against distilled water, and the resulting product was lyophilized. The amounts of Cy5.5 in the FA-GC and GC were similar as $\sim 0.7 \mathrm{wt} \%$, as determined by Cy5.5 absorbance at $690 \mathrm{~nm}$ in DMSO.

\section{Primary spinal neuron culture}

Primary spinal cord neurons were obtained from Sprague Dawley rat E15 embryo spinal cords according an established protocol [39]. In brief, E15 rat spinal cords were isolated and placed in Leibovitz's L-15 medium. Meninges were carefully removed, the spinal cords were cut into small pieces and dissociated with $0.05 \%$ trypsin/EDTA for $15-20$ min at $37{ }^{\circ} \mathrm{C}$ and gently triturated. After adhering at $37^{\circ} \mathrm{C}$ for $30 \mathrm{~min}$ to eliminate glial cells and fibroblasts, neurons were plated on poly-L-lysine pre-coated 48 -well plates. Neurons were incubated in a humidified atmosphere containing $5 \% \mathrm{CO}_{2}$ at $37{ }^{\circ} \mathrm{C}$ with DMEM including $10 \%$ heatinactivated fetal calf serum, $5 \%$ heat-inactivated horse serum, and $2 \mathrm{mM}$ glutamine. After $16 \mathrm{~h}$, the medium was replaced with Neurobasal medium with $2 \% \mathrm{~B} 27,1 \% \mathrm{~N} 2$, and $2 \mathrm{mM}$ glutamine. On day 3 in vitro, $5 \mu \mathrm{M}$ cytosine- $\beta$-D-arabinofuranoside was added for $24 \mathrm{~h}$ to inhibit glia cell proliferation. Cells in 48-well plates were cultured with $200 \mathrm{~L}$ medium until experimentation. With this culture protocol, a purity of greater than $87 \%$ spinal cord neuron population was obtained by 7 DIV. All experiments were performed between 7-10 days following initial plating.

\section{Neuroprotective effect of FA-GC nanoparticles for in vitro glutamate-induced exitotoxicity model}

The neurons were incubated with GC $(0.1 \mathrm{mg} / \mathrm{ml}, \mathrm{n}=3)$ and FA-GC nanoparticles $(0.1$ $\mathrm{mg} / \mathrm{ml}, \mathrm{n}=3$ ) for $30 \mathrm{~min}$, following treatment of $100 \mu \mathrm{M}$ glutamate for $24 \mathrm{~h}$. Hoechst 33342 $(10 \mu \mathrm{M})$ was added to the culture at $37^{\circ} \mathrm{C}$ for $15 \mathrm{~min}$ to label all cell nuclei, followed by incubation with PI $(5 \mu \mathrm{g} / \mathrm{ml})$ at room temperature for $10 \mathrm{~min}$ to stain dead cell nuclei. After staining, the medium was removed and cells were washed with $10 \mathrm{mM}$ PBS, following by 10 min treatment with 4\% PFA for cell fixation. The fixed cells were then washed 3 times with PBS and were ready for imaging. Images were taken by phase microscope (Olympus CK2, Japan) at 20x and 40x magnification. The cell viability was determined by counting the number of total and PI stained neuron. 


\section{Contusive spinal cord injury model}

All protocols were approved by the Purdue University Animal Care and Use Committee. Adult Long-Evans rats ( $300 \mathrm{~g}$ ) were anesthetized by $90 \mathrm{mg} / \mathrm{kg}$ ketamine and $5 \mathrm{mg} / \mathrm{kg}$ xylazine. A T10 laminectomy was performed to expose the underlying thoracic spinal cord segment(s). Spinal cord contusion injury was produced using a weight-drop device developed at New York University [40]. The exposed dorsal surface of the cord was subjected to weight-drop impact using a $10 \mathrm{~g}$ rod $(2.5 \mathrm{~mm}$ in diameter) dropped from a height of $12.5 \mathrm{~mm}$. After the injury, the muscles and skin were closed in layers, and rats were placed on a heating pad to maintain the body temperature of the rats until they awoke. The analgestic buprenorphine $(0.05-0.10 \mathrm{mg} / \mathrm{kg})$ was administered every $12 \mathrm{~h}$ through subcutaneous injection for the first 3 days post-surgery for post-operation pain management.

\section{Pharmacokinetics and tissue distribution of FA-GC nanoparticles}

The pharmacokinetics of FA-GC nanoparticles and GC were determined by Cy5.5 fluorescence. FA-GC(-Cy5.5) and $\mathrm{GC}(-\mathrm{Cy} 5.5)(16 \mathrm{mg} / \mathrm{kg}, 1 \mathrm{ml}$ in saline) were intravenously administrated to SCI rats ( $\mathrm{n}=3$ for each group) through a jugular vein at $2 \mathrm{~h}$ post contusive injury $(\mathrm{n}=3)$. Blood samples $(50 \mu \mathrm{l})$ were drawn through another jugular vein at determined times. The fluorescence intensities of Cy5.5 labeled to FA-GC nanoparticles and GC in blood were measured by a fluorescence spectrometer (SpectraMax M5, Molecular Devices, CA) with excitation at $675 \mathrm{~nm}$ and emission at $695 \mathrm{~nm}$. The dataset was fit to a one-compartment pharmacokinetic model:

$$
\mathrm{y}=\mathrm{A} \mathrm{e} \mathrm{e}^{(-x / \mathrm{t})}+\mathrm{y}_{0}
$$

The fluorescence imaging of FA-GC(-Cy5.5) in blood samples drawn at different time points was performed using IVIS Lumina (Caliper Life Sciences, Inc., MA) with excitation at $640 \mathrm{~nm}$ and emission at 695-770 $\mathrm{nm}$. For biodistribution study, FA-GC(-Cy5.5) nanoparticles was intravenously injected at $2 \mathrm{~h}$ post injury. At 1 day after the injection, the rats were sacrificed via transcardial perfusion with saline and the tissues were harvested. Cy5.5 in the tissues was imaged by IVIS Lumina. Quantitative analysis for the tissue distribution of FA-GC nanoparticles was performed using the Living Imaging Software (Caliper Life Sciences, Inc., MA).

\section{Nonlinear optical imaging of injured spinal cord tissue}

The injured spinal cord tissue harvested in the tissue distribution study of FA-GC nanoparticles was cross-sectioned at $200 \mathrm{~m}$ thickness using an oscillating tissue slicer (Electron Microscopy Sciences, Inc., PA). For simulated Raman loss (SRL) imaging, a Ti:sapphire laser (Chameleon Vision, Coherent) of $140 \mathrm{fs}$ pulse duration, $80 \mathrm{MHz}$ repetition rate was tuned at $830 \mathrm{~nm}$ to pump an optical parametric oscillator (OPO, APE compact OPO, Coherent) [41]. Based on the $\mathrm{C}-\mathrm{H}$ molecular vibration, the OPO provided the Stokes beam at $\sim 1090 \mathrm{~nm}$, and then collinearly combined with the pump beam and sent to a laser scanning microscope (BX51, Olympus). The pump and Stokes beam were then focused into the sample using a water immersion objective lens (XLPlan N 25X, NA 1.05, Olympus). The forward SRL signal was collected by an oil condenser (U-AAC, NA 1.4, Olympus) and 
detected by a photodiode (S3994-01, Hamamatsu). The fluorescence signal was collected backward with a photomultiplier tube (H7422P-40, Hamamatsu) after an optical filter (715/60, Chroma). Pixel dwell time was $4 \mu$ for each image.

\section{Locomotor scoring after FA-GC nanoparticle treatment}

Rats were randomly divided into 3 groups according to the treatments received: $1 \mathrm{ml}$ FA-GC nanoparticles ( $16 \mathrm{mg} / \mathrm{kg}$ in saline; $\mathrm{n}=12$ ), $1 \mathrm{ml}$ methylprednisolone sodium succinate (MP, $30 \mathrm{mg} / \mathrm{kg} ; \mathrm{n}=5)$, and isovolumetric dose of saline $(\mathrm{n}=12)$. Treatments were administrated at $2 \mathrm{~h}$ post injury by intravenous jugular vein injection. Bladder expression was manually carried out 3 times daily until reflex bladder emptying was established. The locomotor recovery was assessed using the Basso Beattie Bresnahan (BBB) locomotor rating score [38]. Two lab members conducted the test independently and agreement on the score was reached before the scores were finalized. The scores were recorded at day 1, 7, 14, 21, and 28. The locomotor behaviors were recorded via a video camera.

\section{Immunofluorescence analysis of spinal cord tissue}

At 28 days after the injury, the rats were anesthetized and transcardially exsanguinated with $150 \mathrm{ml}$ physiological saline followed by fixation with $300 \mathrm{ml}$ of ice-cold $4 \%$ paraformaldehyde in PBS (PH 7.4). A $1.5 \mathrm{~cm}$ thoracic spinal cord segment at the lesion center was dissected and then fixed $4 \mathrm{~h}$ by $4 \%$ paraformaldehyde in PBS (pH 7.4), and transferred to $30 \%$ sucrose in PBS (pH 7.4). The cord segments were embedded in tissueembedding medium, and $30 \mathrm{~m}$ sagittal sections were cut on a cryotome and mounted onto glass slides.

For immunofluorescence staining, the sections were permeabilized and blocked with $0.3 \%$ Triton X-100/10\% normal goat serum (NGS) in PBS (pH 7.4) for 30 min. Primary antibodies were then applied to the sections overnight at $4{ }^{\circ} \mathrm{C}$. Glia fibrillary acidic protein (GFAP, diluted 1:220, Abcam, Cambridge, MA, USA), ED-1 (diluted 1:50; Millipore, St. Charles, MO, USA) and SMI31 (diluted 1:500, Abcam, Cambridge, MA, USA) were used as the primary antibody to identify astrocyte and macrophage/activated microglia and axons, respectively. The sections were incubated the following day for $2 \mathrm{~h}$ at room temperature with secondary antibodies (Alexa Fluor 488, Invitrogen; Cy3, Invitrogen), washed, mounted, and then examined using an Olympus IX70 confocal microscope equipped with a FluoView program. The cavity volume measurement and $3 \mathrm{D}$ construction were conducted by a Neurolucida program, GFAP ${ }^{+}$and ED- $1^{+}$fluorescence intensity were measured by Image $\mathrm{J}$. The SMI $31^{+}$axon number was counted manually by image $\mathrm{J}$.

Luxol fast blue (LFB) staining was used to observe the spared myelin, the protocols has been described before [42]. The slides were dehydrated with $70 \%$ and $95 \%$ alcohol for 2 min each, and then they were immersed with $0.1 \% \mathrm{LFB}$ solution at $37^{\circ} \mathrm{C}$ for $4 \mathrm{~h}$. After cooling at $4{ }^{\circ} \mathrm{C}$ for $20 \mathrm{~min}$, the slides were dipped in $95 \%$ alcohol 5 times and $\mathrm{dH}_{2} \mathrm{O}$ for 1 $\mathrm{min}$, then they were cleared and sealed. To calculate the percentage of spared myelin, we firstly transferred the image to black, then we selected all the LFB stained area and measured it. After measuring the whole spinal cord area, we calculate the ratio of selected black area to the whole section area, which represent the percentage of spared myelin. 
To define the cavity area, we performed hematoxylin and eosin (H\&E) staining. Briefly, after drying the section, we stained the tissue in $50 \mathrm{ml}$ conical tube filling with $0.1 \%$ hematoxylin, then the section was rinsed in cool running $\mathrm{ddH}_{2} \mathrm{O}$ for $5 \mathrm{~min}$. After dipping the section in $0.5 \%$ Eosin, we put the section in distilled $\mathrm{H}_{2} \mathrm{O}, 50 \%$ alcohol, $70 \%$ alcohol, 95\% alcohol, and $100 \%$ alcohol, then we dip the section in xylene several times, clean the slide, and seals it.

For assessment of axons, microphages, astrocyte, and myelin, four sections from FA-GC treated tissue and 3 sections from saline treated control group at epicenter were selected. For each section, three perilesion areas were chosen randomly to do the statistical analysis. Fluorescence intensity was used to represent the astrocyte, macrophages reaction, the axon number was counted to measure the spared axon, and the percentage of myelin stained area indicate the spared myelin. For the measurement of cavity volume percentage, $1 \mathrm{~cm}$ segment of thoracic spinal cord ( $\mathrm{n}=3$ for each group) including the lesion epicenter was dissected and sectioned by transversely at $20 \mu \mathrm{m}$ thickness by cryotome and mounted to glasses. 60 sections per each $1 \mathrm{~cm}$ length spinal cord were used to calculate the cavity volume, the whole spinal cord volume, and 3-dimentional reconstruction by Neurolucida software (MicroBrightfield, Inc.). The percentage of cavity volume to spinal cord volume was use to assess the neuroprotective effect of FA-GC nanoparticles.

\section{In vivo toxicity analysis}

Long-Evans adult male rats were randomized into the GC-FA nanoparticle-treated group $(\mathrm{n}=3)$ or the saline-treated group $(\mathrm{n}=3)$. Each rat $(\sim 300 \mathrm{~g}$ by weight) received $1 \mathrm{ml}$ FA-GC nanoparticles (16 mg/kg in saline) or $1 \mathrm{ml}$ saline solution through jugular vein injection. Blood samples $(1 \mathrm{ml})$ were drawn through the jugular vein at day 1 and day 28 post treatment. Haematology and serum analysis were performed by Antech Diagnostics, Inc. in a blinded manner. The rats were then sacrificed and tissues including liver, lung, spleen, and kidneys were fixed in $10 \%$ neutral buffered formalin for at least $48 \mathrm{~h}$, embedded into paraffin. Sections of $5 \mathrm{~m}$ thickness were stained with haematoxylin and eosin in Purdue University Histopathology Lab. The slides were then examined on a Nikon microscope equipped with a charge-coupled device camera.

\section{Statistical analysis}

Values are expressed as mean \pm SEM, and statistical comparisons between groups were made using the Student's t-test and a $P$ value of $<0.05$ was considered significant.

\section{Results}

\section{Physicochemical characteristics of FA-GC nanoparticles}

Different amounts of FA (feed molar ratio of 45-180 mol FA to $1.0 \mathrm{~mol} \mathrm{GC}$ ) were conjugated to $\mathrm{GC}\left(\mathrm{M}_{\mathrm{w}}=250 \mathrm{KDa}\right)$ (Fig. 1a). With three different feed ratios of FA, FA-GC polymers with different degree of substitutions of FA were obtained, as listed in Table S1. The presence of FA in FA-GC polymer was confirmed by characteristic peaks at 6-8 ppm in ${ }^{1} \mathrm{H}-\mathrm{NMR}$ spectra (data not shown), and the amide linkage between GC and FA was confirmed by an increase in the amide peak at $1656 \mathrm{~cm}^{-1}$ in FT-IR spectra (Fig. 1b). Self- 
assembled FA-GC nanoparticles were generated by sonication in aqueous conditions. The zeta-potentials and average diameters of FA-GC nanoparticles were measured using a zetapotential dynamic light scattering analyzer, respectively (Table S1). FA-GC nanoparticles showed similar positive zeta-potentials, implying the GC shell composes the nanoparticle surface. On the other hand, FA-GC nanoparticles with a degree of substitution of 12.8 had smaller diameter $(236 \mathrm{~nm})$ compared to other nanoparticles, and their spherical morphology was confirmed by transmission electron microscopy (Fig. 1c). Since smaller FA-GC nanoparticle size may allow more nanoparticles to accumulate at the injured spinal cord tissue, it was decided to use FA-GC nanoparticles with a degree of substitution of 12.8 in the following studies unless otherwise noted.

\section{Neuroprotective effect of FA-GC nanoparticles against glutamate-induced excitotoxicity}

Since glutamate level increase is the most significant pathological feature of SCI, we first confirmed the neuroprotective effect of FA-GC nanoparticles on primary spinal cord neuronal culture using a glutamate-induced excitotoxicity model. In the control group, spinal cord neurons showed clear neuronal cell bodies and extended neurites (Fig. 2a, control, yellow arrow). After exposure to glutamate (Glu) for $24 \mathrm{~h}$, neuronal loss and breakdown of neurites were clearly seen (Fig. 2a, Glu, red arrow). Pre-treatment by GC partially reduced neuronal loss and suppressed neurite degeneration (Fig. 2a, Glu+GC, yellow arrow). Pretreatment by FA-GC nanoparticles showed greater effect on prevention of neuronal loss and neurite disintegration as compared to the use of GC alone (Fig. 2a, Glu+FA-GC, yellow arrow). Neuron viability percentage (\%) was quantified using Hoechst/propidium iodide (PI) staining (Fig. 2a, right column). Administration of glutamate for $24 \mathrm{~h}$ led to massive neuronal loss and only $48 \%$ survived the glutamate insult. Pre-treatments by GC polymer or FA-GC nanoparticles significantly increased neuronal survival by $81 \%$ and $98 \%$, respectively (Fig. 2b). These results demonstrate the neuroprotective effect of both GC and FA-GC nanoparticles. The better survival of neurons after FA-GC nanoparticle treatment than with the GC polymer treatment alone indicated the added neuroprotective effect of FA conjugation.

\section{Pharmacokinetics and bioavailability of FA-GC nanoparticles in $\mathrm{SCl}$ animals}

Next, we characterized the blood retention time and bioavailability of FA-GC nanoparticles for SCI using fluorescence labeling. As shown in Fig. 3a, FA-GC nanoparticles exhibited a long retention time in blood with a half-life of $20 \mathrm{~h}$ determined by a one-compartment model. In comparison, the non-modified GC polymer showed a half-life of $6 \mathrm{~h}$. We also examined the bioavailability of FA-GC nanoparticles in injured and uninjured rat spinal cords at 1 day post injection. The fluorescence of Cy5.5 conjugated FA-GC nanoparticles was detected only at the lesion site of the injured spinal cord (Fig. 3b, insert). The noninjured spinal cord showed a background autofluorescence that was 15 times weaker compared to the FA-GC fluorescence in the injured cord.

To investigate cellular level localization of FA-GC nanoparticles in the injured spinal cord, we used two-photon excitation fluorescence and stimulated Raman loss microscopic imaging technology (Fig. 3c). FA-GC nanoparticles were highly accumulated in the gray matter compared to the white matter at $1 \mathrm{~d}$ post injury (Fig. 3c-1). In the gray matter, 
aggregation of red blood cells and blood clots was observed, indicating blood vessel damages induced by contusive impact (Fig. 3c-2). FA-GC was present in the ventral portion of the dorsal funiculus, close to the central canal (Fig. 3c-4). The white matter was not seriously damaged as compare to gray matter $($ Fig. 3c-3, 5). In fact, the ventral white matter remained morphologically intact with the absence of fluorescence of Cy5.5 conjugated FAGC nanoparticles (Fig. 3c-5). Together, these results demonstrated selective accumulation of FA-GC nanoparticles at the lesion site.

\section{Functional restoration of FA-GC nanoparticles in contusive $\mathrm{SCl}$ rats}

To determine the effectiveness of FA-GC in functional recovery, we employed the Basso Beattie Bresnahan (BBB) locomotor rating scale to assess locomotor recovery in rats received intravenous injection of FA-GC nanoparticles. The control rats received either saline or MP injection. All injections were carried out at $2 \mathrm{~h}$ after contusive SCI, as shown schematically in Fig. 4a. The BBB scores were recorded at days 1, 7, 14, 21, and 28 after SCI in a blinded manner for all three groups (Fig. 4b). On day 28, an increase of 4.9 points in the BBB scale was seen in the FA-GC treated group compared to the saline treated group, and an increase of 5.7 points in the FA-GC treated group compared to the MP treated group (FA-GC: $14.9 \pm 0.7$, saline: $10.0 \pm 0.7$; MP: $9.2 \pm 0.2$ ). The score of 14.9 in the FA-GC treated group indicates consistent weight-supported plantar steps and frequent forelimb-hindlimb coordination, whereas the BBB scores of 9 to 10 in the MP and saline groups mean that the rats were only able to achieve weight support in stance and there was no coordination between fore- and hindlimbs (Videos S1, S2).

\section{Histological improvement of injured spinal cord by FA-GC treatment}

To determine the anatomical basis of observed functional recovery, we examined several key parameters that were associated with tissue damage and repair. These parameters included densities of axons, astrocytes, macrophages, myelin, and volumes of cavity at day 28 post injury. Astrocytes, which play a major role in the formation of gliosis after SCI [43], were visualized using glial fibrillary acidic protein (GFAP) antibodies. The immunoreactivity of GFAP in the FA-GC group was 50\% of that in the saline group (Fig. 5a), indicating that FA-GC treatment reduced astrogliosis at the lesion site. The macrophages play a major role in inflammatory responses including modulating axon degeneration and myelin clearance after SCI [44]. Measured by ED1 immunofluorescence, FA-GC treatment decreased the density of macrophages by $24 \%$ compared to the saline treated group (Fig. 5b). To determine whether the reduced immunoreactivity of astrocytes and macrophages benefit the survival of axons and myelin, we quantified their densities using SMI31 immunofluorescence and luxol fast blue staining, respectively. Compared to the saline treated group, FA-GC treatment increased the number of spared axons in the epicenter of the spinal cord by 6.6 times (Fig. 5c) and enlarged the luxol fast blue stained area by 2 times (Fig. 5d). These results collectively show that FA-GC treatment not only suppressed astrogliosis and inflammation, but also protected axons and myelin.

In accordance with the cellular responses described above, administration of FA-GC nanoparticles reduced the volume of the lesion cavity (Fig. 6a) as compared to the saline treated group. By hematoxylin and eosin (H\&E) staining and employing the Neurolucida 
system, we reconstructed the spinal cord sections into 3D images and determined the cavity volume (Fig. 6b). The cavity volume of the FA-GC treated group was 2.3 times smaller than that of the saline treated group (Fig. $\mathbf{6 c}$ ). The reduced cavitation further supports the neuroprotective effect of FA-GC nanoparticles.

\section{In vivo toxicity analysis}

We have evaluated both acute and chronic toxicity of FA-GC nanoparticle administration to Long-Evans rats through blood and histological analyses. After saline and FA-GC administrations to rats, blood samples were collected at day 1 and day 28 for acute and chronic toxicity evaluation, respectively. The results of hematology and serum analyses between the FA-GC group and saline treated group were not significantly different (Fig. 7a). The levels of creatinine and alanine transaminase for the FA-GC group were the same as that of the saline group, indicating no damage to the kidney and the liver. The morphology of vital organs was also assessed using H\&E staining. No morphological difference was observed between the groups treated with saline and FA-GC at day 28 post treatment (Fig. 7b). Together, these results revealed no adverse effects of FA-GC nanoparticles in the rat model.

\section{Discussion}

After primary SCI, protection of neurons and glial cells from secondary degeneration is crucial for functional recovery. Currently, methylprednisolone (MP), a steroid drug, is the only option for early pharmacological treatment of SCI, although its therapeutic effect is controversial. Using non-cytotoxic and neuroprotective nanoparticles reported here opens a new opportunity for effective treatment of SCI. Systemic administration of the FA-GC nanoparticles at $2 \mathrm{~h}$-post SCI significantly restored locomotor function compared to MP administration. Theses outcomes demonstrated superior therapeutic effects and increased time window of FA-GC nanoparticles for SCI treatment as compared to other nanomaterials using non-functional and synthetic polymers such as PEG and Poloxamer [19, 45].

FA conjugation to GC polymer enhanced not only the neuroprotective effect, but also modified the pharmacological properties. The FA-GC polymer formed self-assembled nanoparticles, and the nanoparticles demonstrated a long retention time in the blood stream by intravenously administration, compared to GC polymer alone. Moreover, the FA-GC nanoparticles efficiently accumulated to the injury site particularly in the gray matter region which is highly vulnerable to an injury insult. The FA-GC nanoparticles reached the lesion site likely through the ruptured blood capillaries and interrupted brain-spinal cord-barriers. Gray matter in the spinal cord, consisting of neuronal cell bodies, glial cells, and capillaries, routes sensory or motor stimulus to interneurons of the central nervous system [46]. Strongimpact force to the spinal cord can easily break small blood vessels and damage the bloodspinal cord barrier in the gray matter that may cause ischemia and neuronal cell apoptosis [47]. Consequently, secondary degeneration spreads from the gray matter to the white matter $[48,49]$. This pathological progression damages not only neurons and glial cells in the gray matter, but also axons and myelin in the white matter. Targeted delivery of FA-GC nanoparticles into injured gray matter prevented such progression at an early stage, thereby 
protecting axons and myelin in the white matter that transmit locomotor signaling. This mechanism could account for the significant locomotor functional recovery enabled by FAGC treatment.

Although various polymers or nanomaterials have been used for early SCI treatment, they had to be administrated within a short period (less than $15 \mathrm{~min}$ ) after SCI or even before SCI to achieve distinct therapeutic effect [23, 50-52]. Such time windows are not clinically relevant for clinical SCI treatment because it generally requires at least 1 or 2 hours for patient transfer to an emergency department and diagnostic assessment before initial treatment. In this study, we demonstrated a marked therapeutic effect of FA-GC nanoparticles, both histologically and behaviorally, by systemic administration of FA-GC nanoparticle at $2 \mathrm{~h}$ post injury. Our results indicate the promising potential of FA-GC nanoparticles for treating SCI in clinical settings. Moreover, because intravenous administration is simple to implement, our approach is applicable to treat SCI in the field. Notably, we only treated SCI rats at fixed dose of FA-GC nanoparticles at $2 \mathrm{~h}$ post the injury in this pilot study. Further work is needed to validate the effectiveness by assessing preclinical outcomes in terms of animal species, dosage, therapeutic time window, and severity of injuries.

\section{Conclusions}

We have shown high neuroprotective effects of ferulic acid (FA)-glycol chitosan (GC) nanoparticles against spinal cord injury (SCI) with a clinically relevant therapeutic time window. The systemic administration of FA-GC nanoparticles significantly rescued axons and neuron cells at the lesion site, while the number of activated astrocytes and macrophages decreased. These neuroprotective effects consequently led functional recovery following SCI.

\section{Supplementary Material}

Refer to Web version on PubMed Central for supplementary material.

\section{Acknowledgments}

This work was supported by a translational research grant from the Wallace H. Coulter Foundation, NIH R01 CA129287 to KP and JXC, NS059622 and NS050243 to XMX, CDMRP W81XWH-12-1-0562 to XMX and JXC, NSF CHE 0847205 and NIH 8R21GM103454 to ZO. The authors thank Dr. Xiaofei Wang for kind help in surgery, Dr. Kwangmeyung Kim for providing the Cy5.5 dyes, and Dr. Mark Cisneros for critical reading of the manuscript.

\section{References}

1. Thuret S, Moon LDF, Gage FH. Therapeutic interventions after spinal cord injury. Nat Rev Neurosci. 2006; 7:628-43. [PubMed: 16858391]

2. Bradbury EJ, McMahon SB. Spinal cord repair strategies: why do they work? Nat Rev Neurosci. 2006; 7:644-53. [PubMed: 16858392]

3. Liu NK, Xu XM. Phospholipase A2 and its molecular mechanism after spinal cord injury. Mol Neurobiol. 2010; 41:197-205. [PubMed: 20127525]

4. Simon CM, Sharif S, Tan RP, LaPlaca MC. Spinal cord contusion causes acute plasam membrane damage. J Neurotrauma. 2009; 26:563-74. [PubMed: 19260780] 
5. Klussmann S, Martin-Villalba A. Molecular targets in spinal cord injury. J Mol Med. 2005; 83:65771. [PubMed: 16075258]

6. Ducker TB, Kindt GW, Kempe LG. Pathological findings in acute experimental spinal cord trauma. J Neursurg. 1971; 35:700-8.

7. Bracken MB, Shepard MJ, Collins WF, Holford TR, Young W, Baskin DS, et al. A randomized, controlled trial of methylprednisolone or naloxone in the treatment of acute spinal- cord injury. $\mathrm{N}$ Engl J Med. 1990; 322:1405-11. [PubMed: 2278545]

8. Yan P, Xu J, Li Q, Chen S, Kim G-M, Hsu CY, et al. Glucocorticoid receptor expression in the spinal cord after traumatic injury in adult rats. J Neurosci. 1999; 19:9355-63. [PubMed: 10531440]

9. Ito Y, Sugimoto Y, Tomioka M, Kai N, Tanaka M. Does high dose methylprednisolone sodium succinate really improve neurological status in patient with acute cervical cord injury?: A prospective study about neurological recovery and early complications. Spine. 2009; 34:2121-4. [PubMed: 19713878]

10. Tsutsumi S, Ueta T, Shiba K, Yamamoto S, Takagishi K. Effects of the second national acute spinal cord injury study of high-dose methylprednisolone therapy on acute cervical spinal cord injury-results in spinal injuries center. Spine. 2006; 31:2992-6. [PubMed: 17172994]

11. Saracino GAA, Cigognini D, Silva D, Caprini A, Gelain F. Nanomaterials design and tests for neural tissue engineering. Chem Soc Rev. 2013; 42:225-62. [PubMed: 22990473]

12. Kubinová Š , Syková E. Nanotechnology for treatment of stroke and spinal cord injury. Nanomedicine. 2009; 5:99-108. [PubMed: 20025468]

13. Cho Y, Shi R, Borgens R, Ivanisevic A. Repairing the damaged spinal cord and brain with nanomedicine. Small. 2008; 4:1676-81. [PubMed: 18798208]

14. Chvatal SA, Kim Y-T, Bratt-Leal AM, Lee H, Bellamkonda RV. Spatial distribution and acute anti-inflammatory effects of methylprednisolone after sustained local delivery to the contused spinal cord. Biomaterials. 2008; 29:1967-75. [PubMed: 18255138]

15. Tysseling-Mattiace VM, Sahni V, Niece KL, Birch D, Czeisler C, Fehlings MG, et al. Selfassembling nanofibers inhibit glial scar formation and promote axon elongation after spinal cord injury. J Neurosci. 2008; 28:3814-23. [PubMed: 18385339]

16. Wang YC, Wu YT, Huang HY, Lin HI, Lo LW, Tzeng SF, Yang CS. Sustaned intraspinal delivery of neurotropic factor encapsulated in biodegradable nanoparticles following contusive spinal cord injury. Biomaterials. 2008; 29:4546-53. [PubMed: 18774604]

17. Cho Y, Borgens RB. Polymer and nano-technology applications for repair and reconstruction of the central nervous system. Exp Neurol. 2012; 233:126-44. [PubMed: 21985867]

18. Friedman JA, Windebank AJ, Moore MJ, Spinner RJ, Currier BL, Yaszemski MJ. Biodegradable polymer grafts for surgical repair of the injured spinal cord. Neurosurgery. 2002; 51:742-52. [PubMed: 12188954]

19. Borgens RB, Shi R, Bohnert D. Behavioral recovery from spinal cord injury following delayed application of polyethylene glycol. J Exp Biol. 2002; 205:1-12. [PubMed: 11818407]

20. Shi R, Borgens RB. Acute repair of crushed guinea pig spinal cord by polyethylene glycol. J Neurophysiol. 1999; 81:2406-14. [PubMed: 10322076]

21. Marks JD, Pan CY, Bushell T, Cromie W, Lee RC. Amphiphilic, tri-block copolymers provide potent, membrane-targeted neuroprotection. FASEB J. 2001; 15:1107-9. [PubMed: 11292683]

22. Follis F, Jenson B, Blisard K, Hall E, Wong R, Kessler R, et al. Role of poloxamer 188 during recovery from ischemic spinal cord injury: A preliminary study. J Invest Surg. 1996; 9:149-56. [PubMed: 8725553]

23. Shi Y, Kim S, Huff TB, Borgens RB, Park K, Shi R, et al. Effective repair of traumatically injured spinal cord by nanoscale block copolymer micelles. Nat Nano. 2010; 5:80-7.

24. Cheng CY, Su SY, Tang NY, Ho TY, Lo WY, Hsieh CL. Ferulic acid inhibits nitric oxideinduced apoptosis by enhancing GABAB1 receptor expression in transient focal cerebral ischemia in rats. Acta Pharmacol Sin. 2010; 31:889-99. [PubMed: 20644551]

25. Ratih P, Kim S-K. Neuroprotective properties of chitosan and its derivatives. Marine Drugs. 2010; 8:2117-28. [PubMed: 20714426]

26. Koh P-O. Ferulic ccid attenuates the injury-induced decrease of protein phosphatase 2A subunit B in ischemic brain injury. PLoS ONE. 2013; 8:e54217. [PubMed: 23349830] 
27. Cheng CY, Su SY, Tang NY, Ho TY, Chiang SY, Hsieh CL. Ferulic acid provides neuroprotection against oxidative stress-related apoptosis after cerebral ischemia/reperfusion injury by inhibiting ICAM-1 mRNA expression in rats. Brain Res. 2008; 1209:136-50. [PubMed: 18400211]

28. Lin TY, Lu CW, Huang S-K, Wang S-J. Ferulic acid suppresses glutamate release through inhibition of voltage-dependent calcium entry in rat cerebrocortical nerve terminals. J Med Food. 2013; 16:112-9. [PubMed: 23342970]

29. Srinivasan M, Sudheer AR, Menon VP. Ferulic acid: therapeutic potential through its antioxidant property. J Clin Biochem Nutr. 2007; 40:92-100. [PubMed: 18188410]

30. Graf E. Antioxidant potential of ferulic acid. Free Radical Biol Med. 1992; 13:435-48. [PubMed: 1398220]

31. Cho Y, Shi RY, Borgens RB. Chitosan produces potent neuroprotection and physiological recovery following traumatic spinal cord injury. J Exp Biol. 2010; 213:1513-20. [PubMed: 20400636]

32. Liu HT, Li WM, Xu G, Li XY, Bai XF, Wei P, et al. Chitosan oligosaccharides attenuate hydrogen peroxide-induced stress injury in human umbilical vein endothelial cells. Pharmacol Res. 2009; 59:167-75. [PubMed: 19121394]

33. Li J, He J, Yu C. Chitosan oligosaccharide inhibits LPS-induced apoptosis of vascular endothelial cells through the BKCa channel and the p38 signaling pathway. Int J Mol Med. 2012; 30:157-64. [PubMed: 22469656]

34. Zhou SL, Yang YM, Gu XS, Ding F. Chitooligosaccharides protect cultured hippocampal neurons against glutamate-induced neurotoxicity. Neurosci Lett. 2008; 444:270-4. [PubMed: 18755243]

35. Je JY, Kim SK. Reactive oxygen species scavenging activity of aminoderivatized chitosan with different degree of deacetylation. Bioorg Med Chem. 2006; 14:5989-94. [PubMed: 16725329]

36. Lee HJ, Park J, Yoon OJ, Kim HW, Lee DY, Kim DH, et al. Amine-modified single-walled carbon nanotubes protect neurons from injury in a rat stroke model. Nat Nano. 2011; 6:121-5.

37. Na JH, Lee S-Y, Lee S, Koo H, Min KH, Jeong SY, Yuk SH, Kim K, Kwon IC. Effect of the stability and deformability of self-assembled glycol chitosan nanoparticles on tumor-targeting efficiency. J Control Release. 2012; 163:2-9. [PubMed: 22846988]

38. Basso DM, Beattie MS, Bresnahan JC. A sensitive and reliable locomotor rating scale for open field testing in rats. J Neurotrauma. 1995; 12:1-21. [PubMed: 7783230]

39. Jiang XY, Fu SL, Nie BM, Li Y, Lin L, Yin L, et al. Methods for isolating highly-enriched embryonic spinal cord neurons: a comparison between enzymatic and mechanical dissociations. J Neurosci Methods. 2006; 158:13-8. [PubMed: 16787666]

40. Basso DM, Beattie MS, Bresnahan JC. Graded histological and locomotor outcomes after spinal cord contusion using the NYU weight-drop device versus transection. Exp Neurol. 1996; 139:24456. [PubMed: 8654527]

41. Zhang D, Slipchenko MN, Cheng J-X. Highly sensitive vibrational imaging by femtosecond pulse stimulated Raman loss. J Phys Chem Lett. 2011; 2:1248-53. [PubMed: 21731798]

42. Iannotti C, Ping Zhang Y, Shields CB, Han Y, Burke DA, Xu XM. A neuroprotective role of glial cell line-derived neurotrophic factor following moderate spinal cord contusion injury. Exp Neurol. 2004; 189:317-32. [PubMed: 15380482]

43. Fitch MT, Silver J. CNS injury, glial scars, and inflammation: Inhibitory extracellular matrices and regeneration failure. Exp Neurol. 2008; 209:294-301. [PubMed: 17617407]

44. Popovich P, McTigue D. Damage control in the nervous system: beware the immune system in spinal cord injury. Nat Med. 2009; 15:736-7. [PubMed: 19584863]

45. Borgens RB, Bohnert D, Duerstock B, Spomar D, Lee RC. Subcutaneous tri-block copolymer produces recovery from spinal cord injury. J Neurosci Res. 2004; 76:141-54. [PubMed: 15048938]

46. Nahin RL, Madsen AM, Giesler GJ. Anatomical and physiological studies of the gray matter surrounding the spinal cord central canal. J Comp Neurol. 1983; 220:321-35. [PubMed: 6643730]

47. Dumont RJ, Okonkwo DO, Verma S, Hurlbert RJ, Boulos PT, Ellegala DB, et al. Acute spinal cord injury, Part I: Pathophysiologic mechanisms. Clin Neuropharmacol. 2001; 24:254-64. [PubMed: 11586110] 
48. David S, Kroner A. Repertoire of microglial and macrophage responses after spinal cord injury. Nat Rev Neurosci. 2011; 12:388-99. [PubMed: 21673720]

49. Hagg T, Oudeag M. Degenerative and spontaneous regenerative processes after spinal cord injury. J Neurotrauma. 2006; 23:263-80.

50. Dugan LL, Turetsky DM, Du C, Lobner D, Wheeler M, Almli CR, et al. Carboxyfullerenes as neuroprotective agents. Proc Natl Acad Sci. 1997; 94:9434-9. [PubMed: 9256500]

51. Kim YT, Caldwell J-M, Bellamkonda RV. Nanoparticle-mediated local delivery of methylprednisolone after spinal cord injury. Biomaterials. 2009; 30:2582-90. [PubMed: 19185913]

52. Chen CL, Chang SF, Lee D, Yang LY, Lee YH, Hsu C, et al. Bioavailability effect of methylprednisolone by polymeric micelles. Pharm Res. 2008; 25:39-47. [PubMed: 17990084] 
a
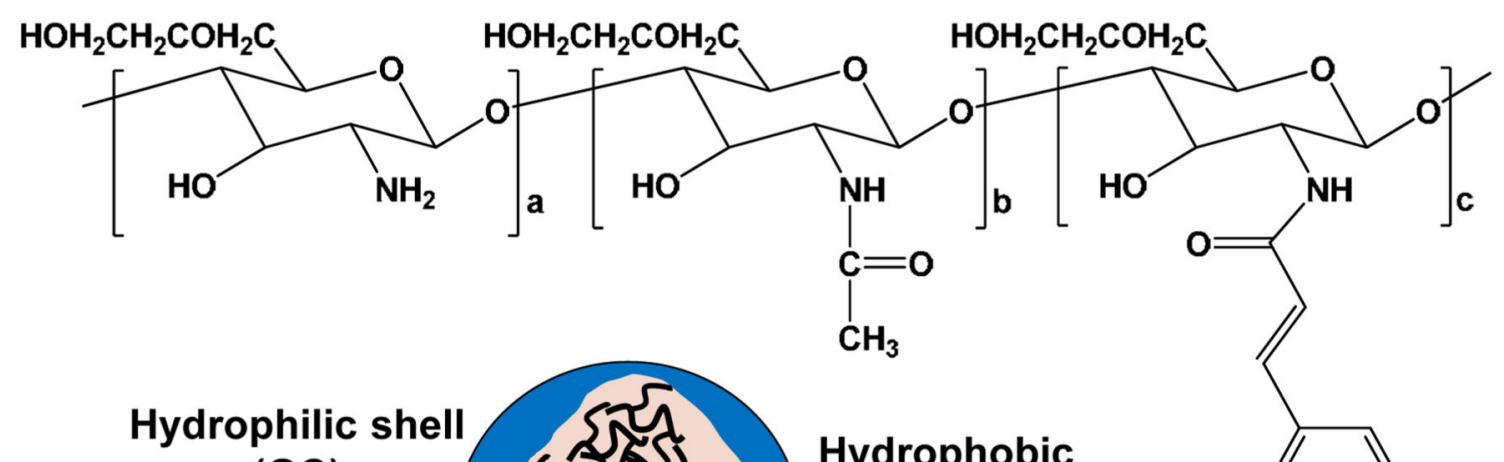

(GC)
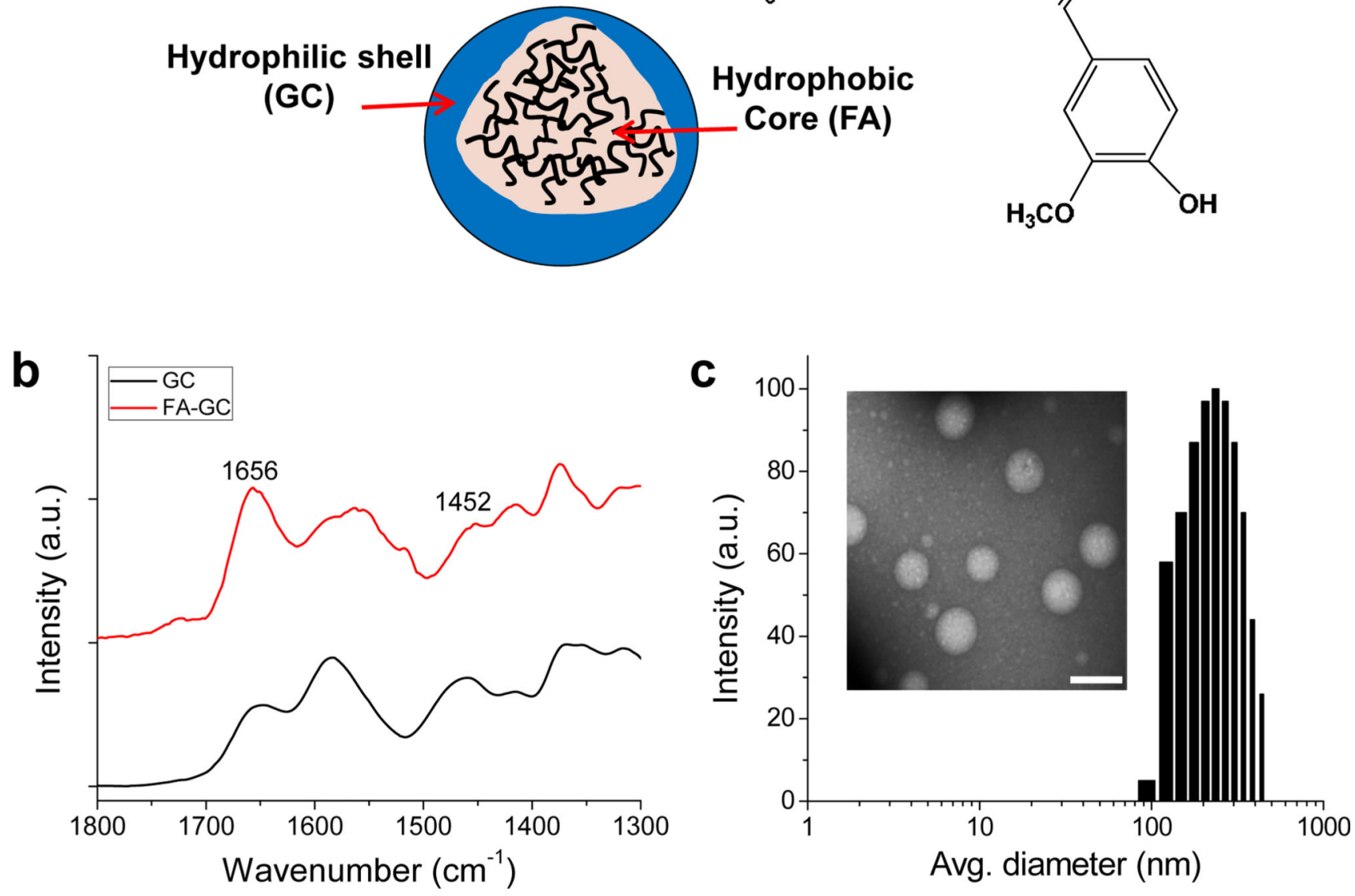

Figure 1. FA-GC nanoparticles

(a) Chemical structure and schematic illustration of FA-GC nanoparticles. (b) FT-IR spectrum of FA-GC polymer. (c) Size distribution and TEM image of FA-GC nanoparticles (Scale bar: $300 \mathrm{~nm}$ ). 


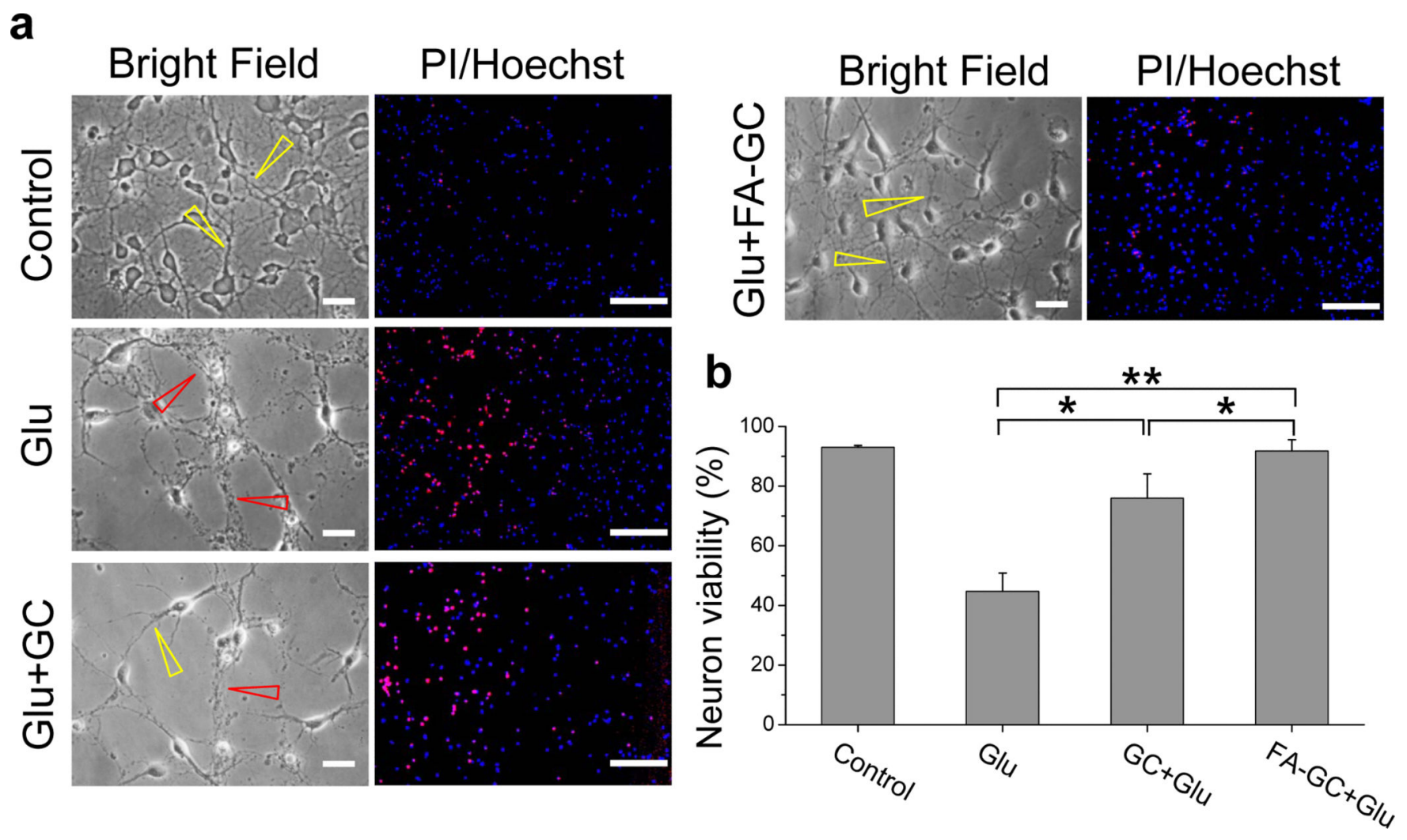

Figure 2. Neuroprotective effect of FA-GC on primary spinal cord neurons after glutamateinduced excitotoxicity

(a, left column) Bright field images showed morphological changes of primary spinal cord neurons in treatment conditions of control, glutamate (Glu, $100 \mu \mathrm{M})$, Glu + GC $(0.1 \mathrm{mg} / \mathrm{ml})$ or Glu + FA-GC $(0.1 \mathrm{mg} / \mathrm{ml})$ for $24 \mathrm{~h}$. Yellow and red arrows indicate intact and degenerated axons in the neurons, respectively. (a, right column) Fluorescence images of propidium iodide (PI, red, marker of dead cells) and/or Hoechst (blue, nuclear marker for both survival and dead cells) stained neurons. (b) Quantitative results of percent viability of neurons (Scale bar: $20 \mu \mathrm{m}) . *, P<0.05, * *, P<0.001$ 

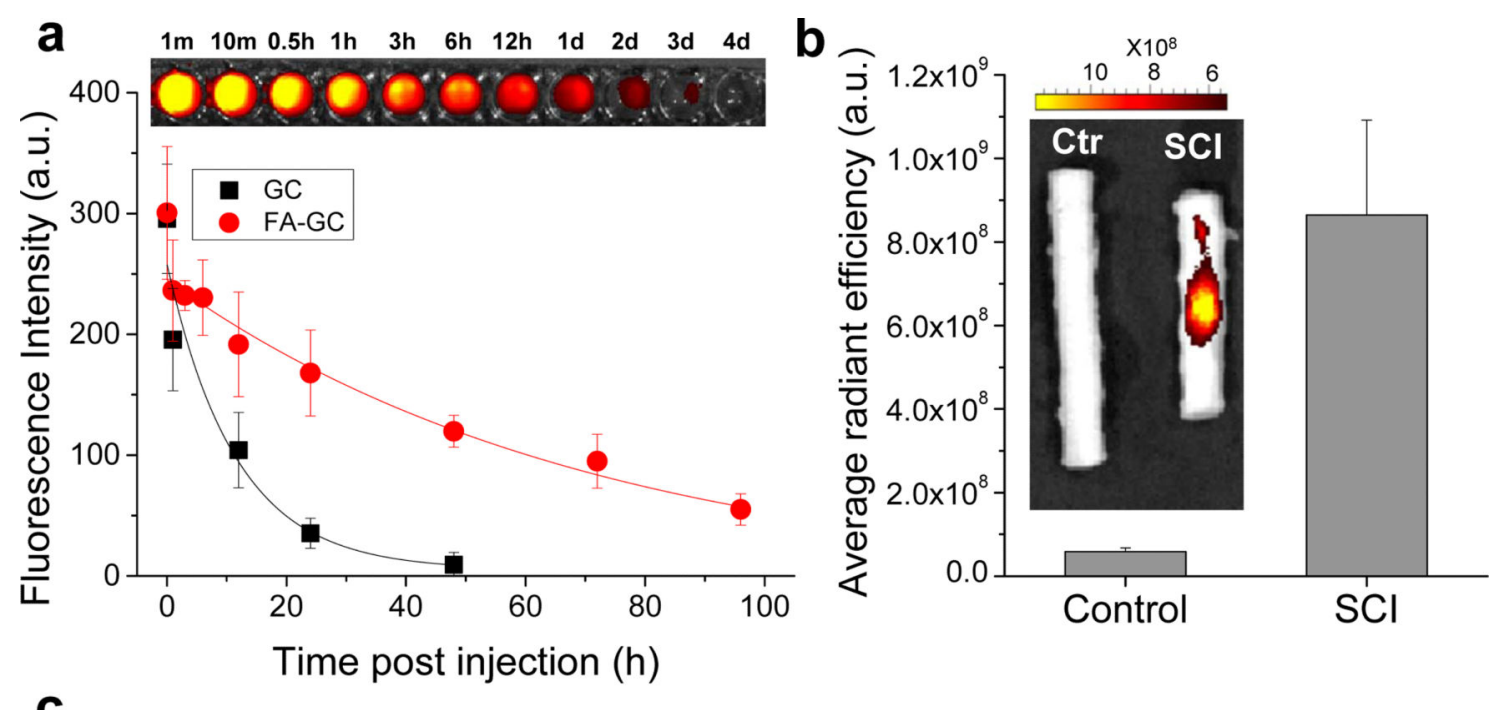

C
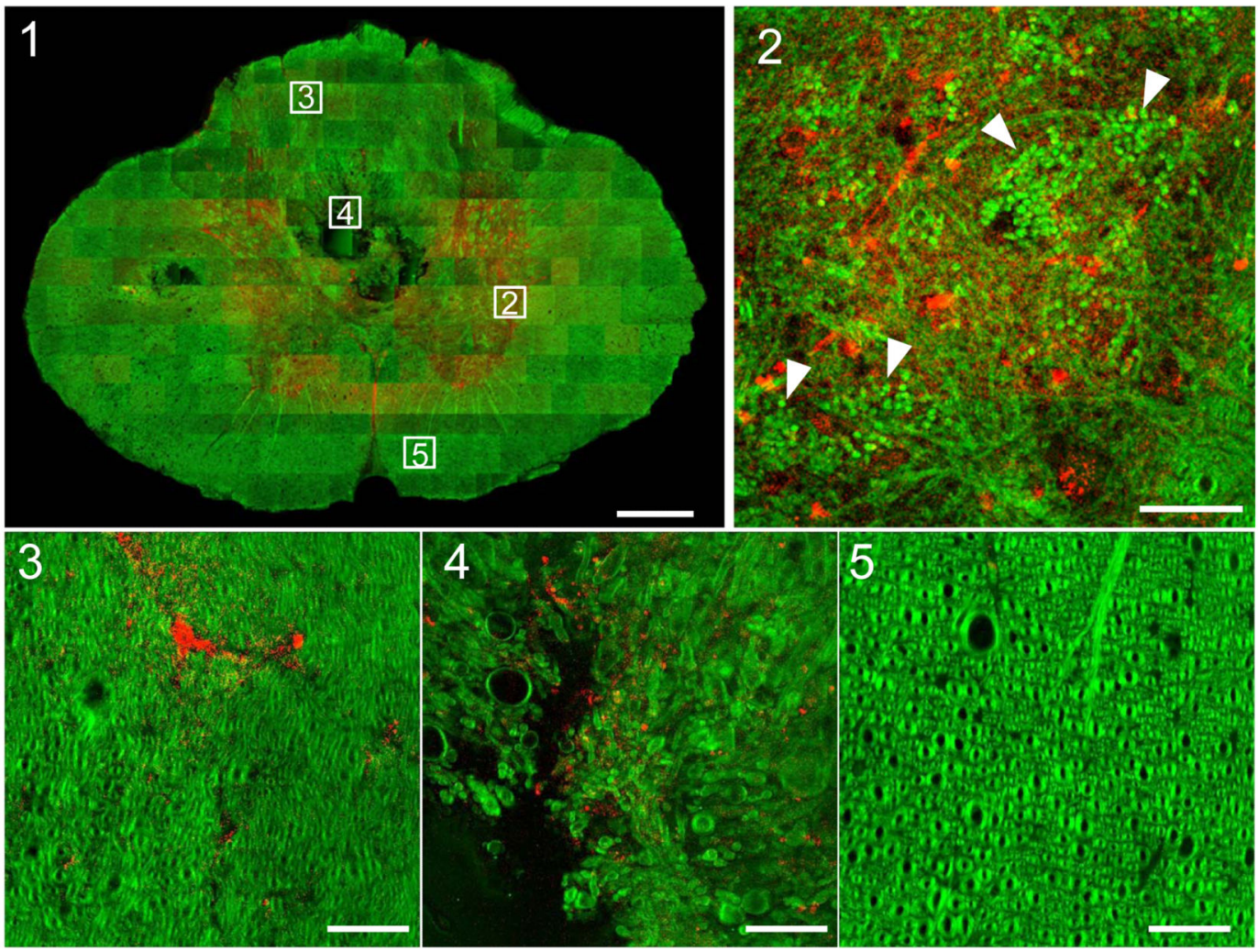

Figure 3. FA-GC nanoparticles exhibited long blood retention time and targeted delivery to injured spinal cord

(a) Blood retention kinetics of FA-GC(-Cy5.5) and GC(-Cy5.5) in SCI rats. FA$\mathrm{GC}(-\mathrm{Cy} 5.5)$ and $\mathrm{GC}(-\mathrm{Cy} 5.5)$ (both at $16 \mathrm{mg} / \mathrm{kg}, 1 \mathrm{ml}$ in saline) were intravenously injected at $2 \mathrm{~h}$ post $\mathrm{SCI}$. The data were fitted with a one-compartment model $\left(\mathrm{y}=\mathrm{Ae} \mathrm{e}^{(-\mathrm{x} / \mathrm{t})}+\mathrm{y}_{0}\right)$. The Fluorescence of FA-GC(-Cy5.5) in blood samples, drawn at different time points, were visualized (top). (b) Fluorescence imaging and quantification of FA-GC(-Cy5.5) in normal and injured spinal cords. (c) Distribution of FA-GC(-Cy5.5) in injured spinal cord. FA-GC and cord were visualized using two-photon fluorescence for Cy5.5 (red) and stimulated 
Raman loss signal from $\mathrm{C}-\mathrm{H}$ vibration (green), respectively. A cross section through the injury epicenter shows the distribution of FA-GC (c1). Dotted squares represent high magnified images of the distribution of FA-GC (red) in the gray matter (c2), the dorsal funicular white matter (c3), the ventral portion of the dorsal funiculus (c4), and the ventral funiculus (c5). White arrows in c2 indicate packed red blood cells (Scale bar: $100 \mu \mathrm{m}$ for C1 and $5 \mu \mathrm{m}$ for $\mathrm{c} 2-5)$. 


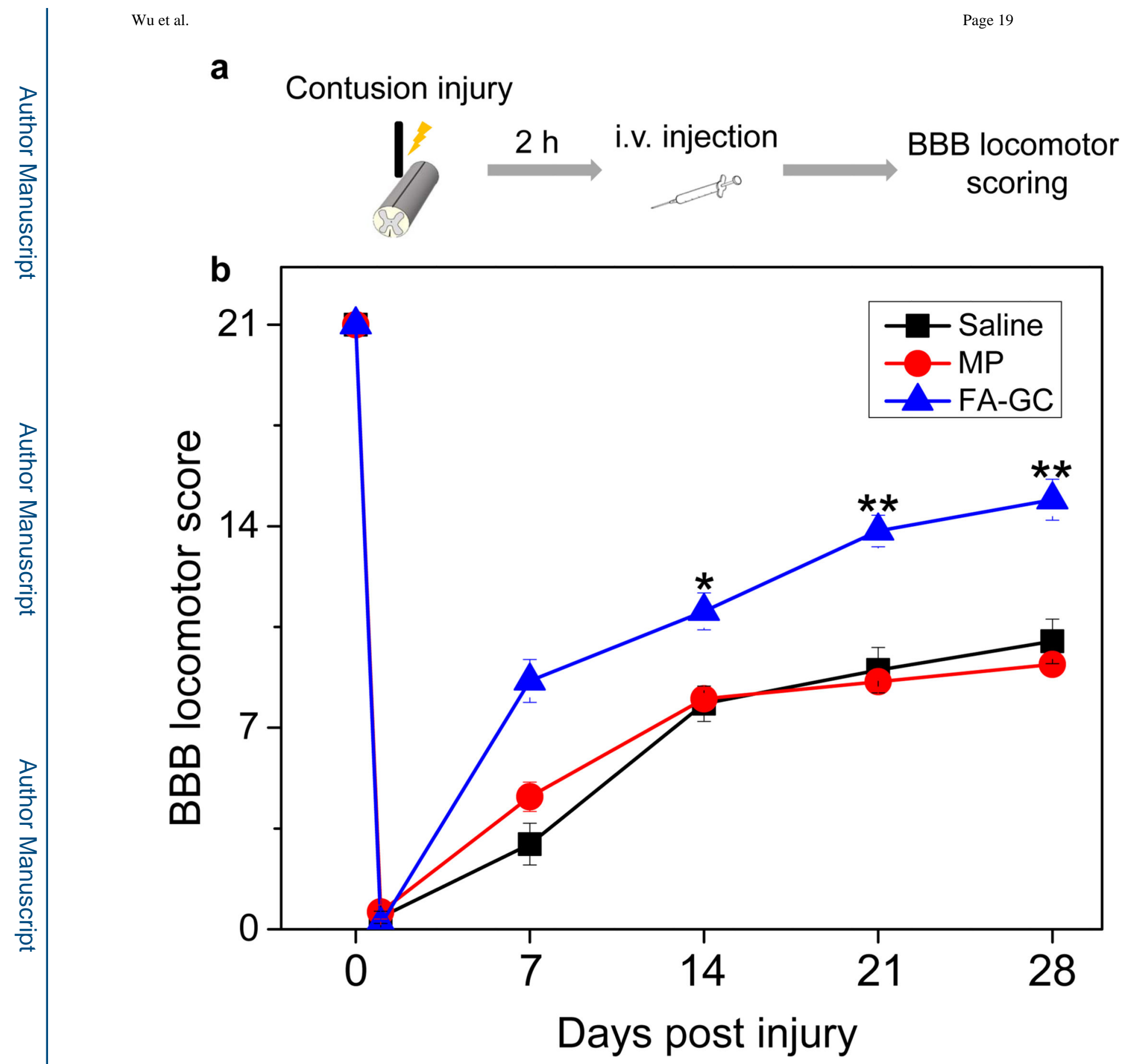

Figure 4. FA-GC treatment promoted locomotor recovery after SCI

(a) Schematic diagram of experimental design. (b) BBB locomotor rating scale performed in rats that received saline $(\mathrm{n}=9)$, methylprednisolone $(M P, \mathrm{n}=5)$, and FA-GC $(\mathrm{n}=10)$ at $2 \mathrm{~h}$ post SCI. Scores were recorded at day $1,7,14$, and 28 post injury in a blinded manner. ${ }^{*}, P$ $<0.05, * *, P<0.01$. 
a

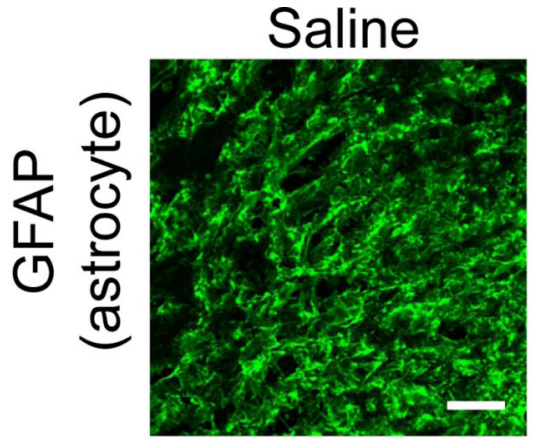

b

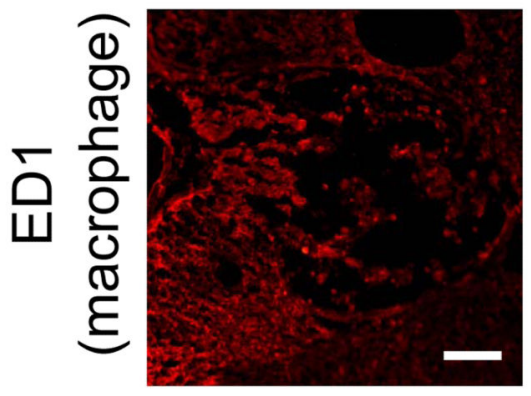

C

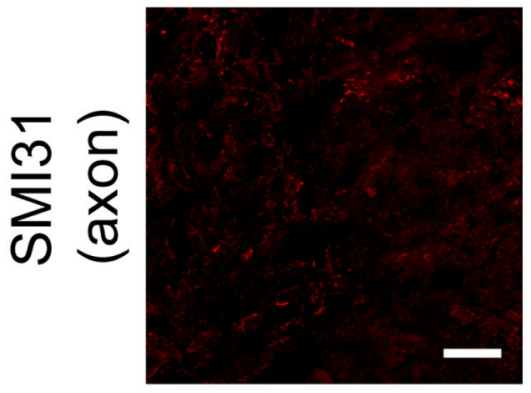

d

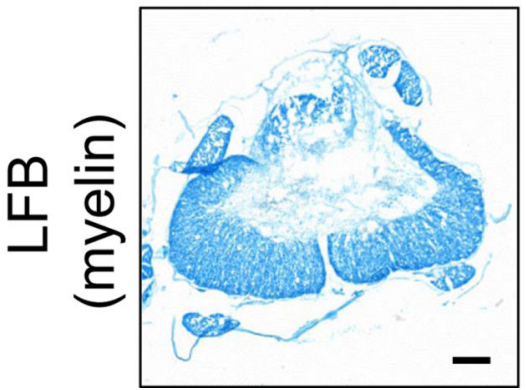

FA-GC
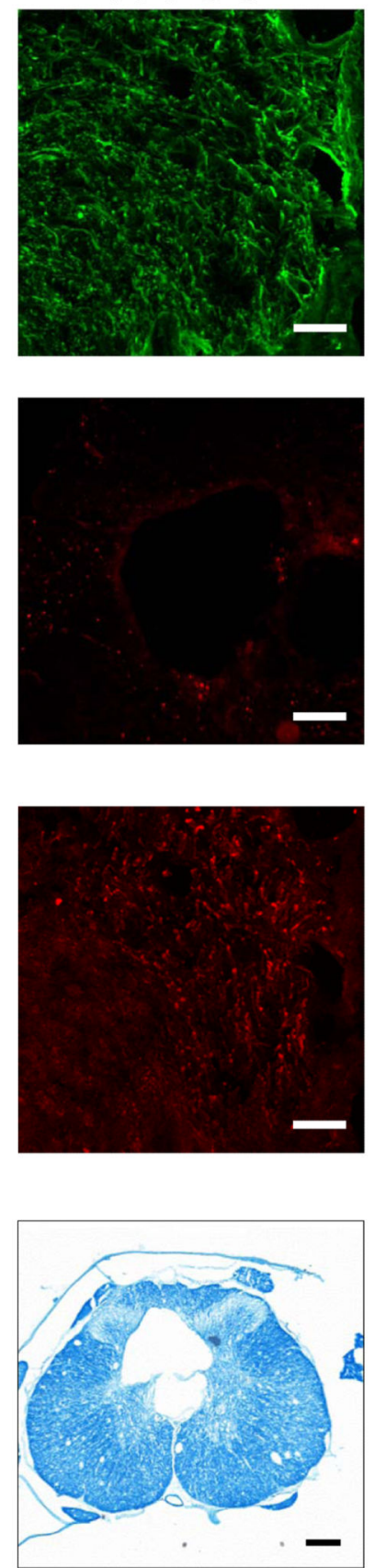
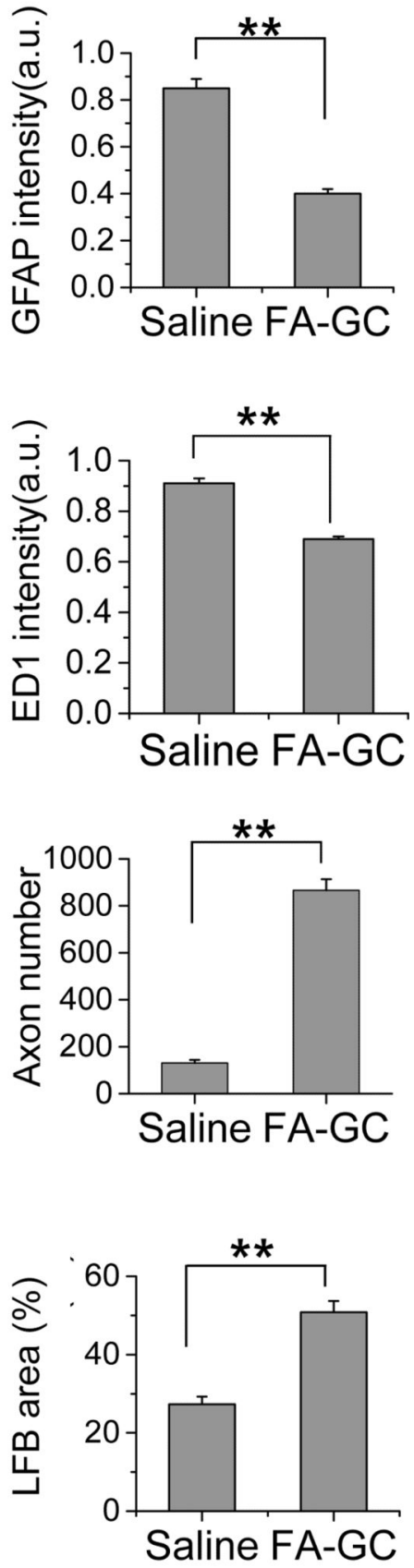

Figure 5. FA-GC treatment improved histological outcomes

(a-b) Florescence images of GFAP+ and ED1+ cells in injured spinal cord at 28 day after saline and FA-GC treatments. The graphs right beside the image are the quantitative analysis of fluorescence intensity, showing FA-GC is capable of reduce the astrocyte and macrophage/microglia reaction. (c) Comparison of spared axons between two groups indicated by SMI31 stained axons, and the graph right beside the images is the quantitative number counting results, indicating an increased number of spared axons. (d) Luxol fast blue (LFB) staining of injured spinal cord for saline and FA-GC treated groups. The graph beside 
the images is the percentage of LFB staining area in the whole spinal cord. **, $P<0.001$; $\mathrm{n}=3-4$. (Scale bar: $100 \mu \mathrm{m})$. 
a
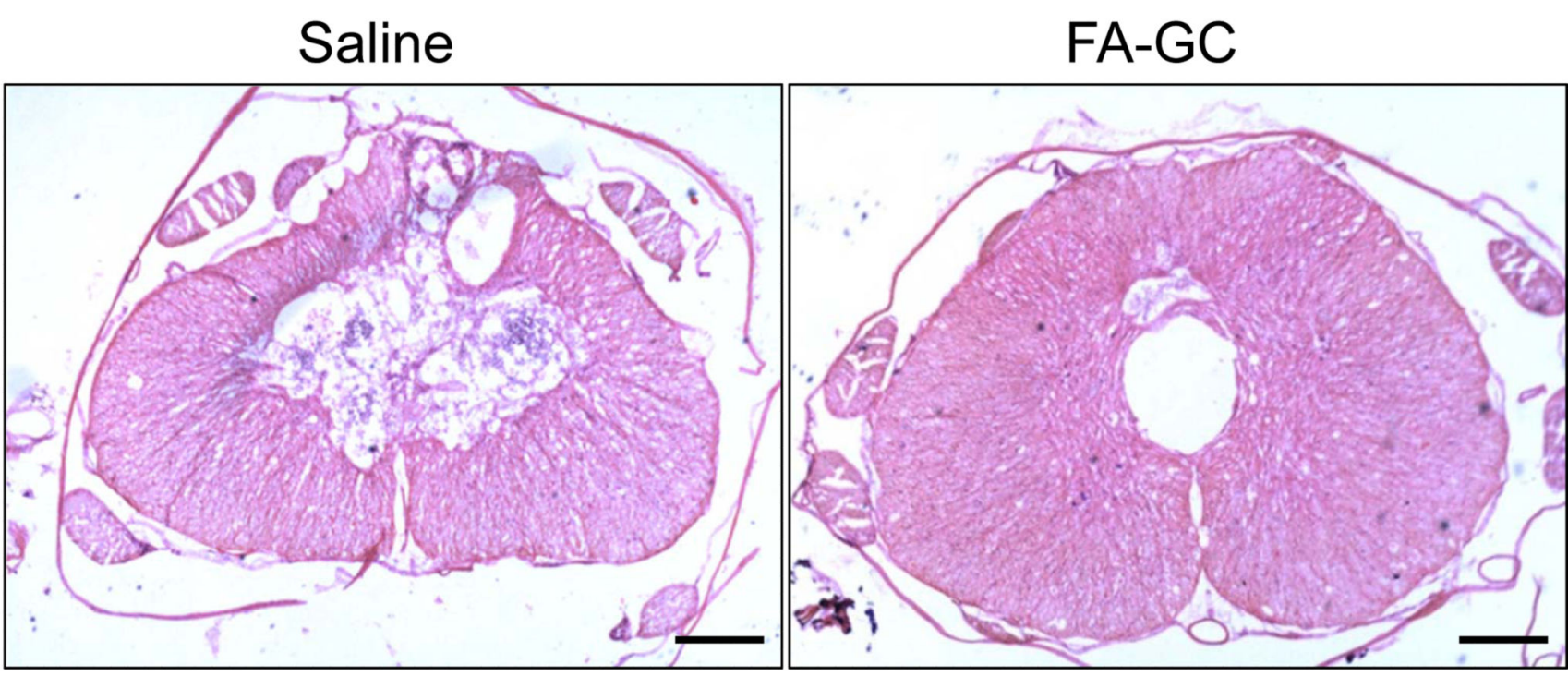

b

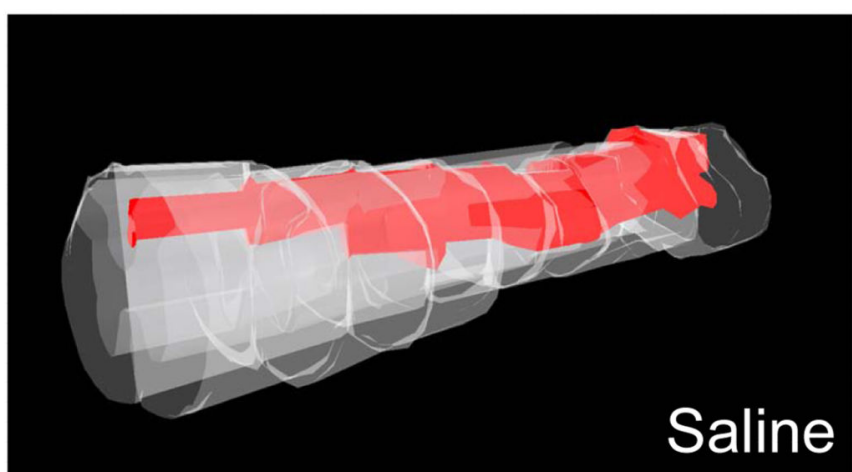

C
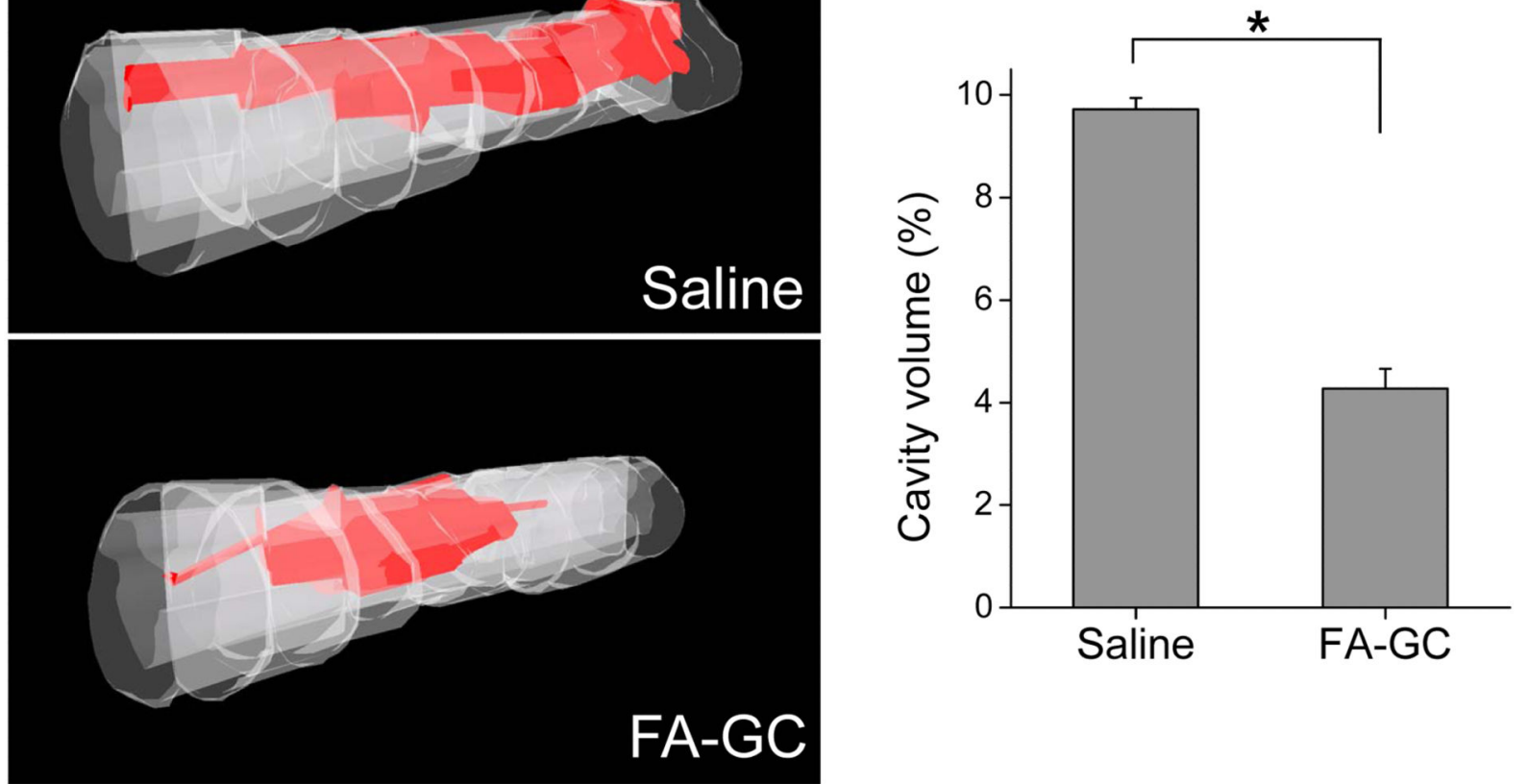

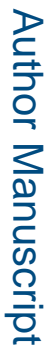

Figure 6. FA-GC nanoparticles reduces cavitation following T10 contusion SCI

(a) Spinal cord harvest 4 weeks post-SCI showed reduced cavitation through hematoxylin and eosin (H\&E) staining with FA-GC treatment compare to saline treated animals. (b) 3D reconstruction of cavity volume from representative cases indicating the neuroprotective effects of FA-GC nanoparticles. (c) Quantification of cavity volume, illustrating the significantly decreased cavity volume in FA-GC treated animals compare to saline control. *, $P<0.05 . \mathrm{n}=3$. (Scale bar: $100 \mu \mathrm{m})$. 
a
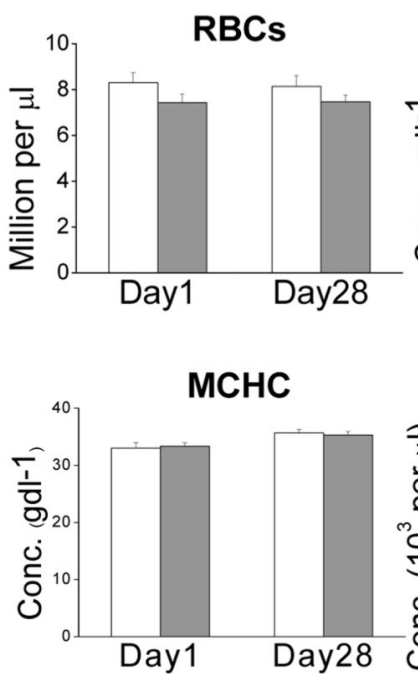

Saline
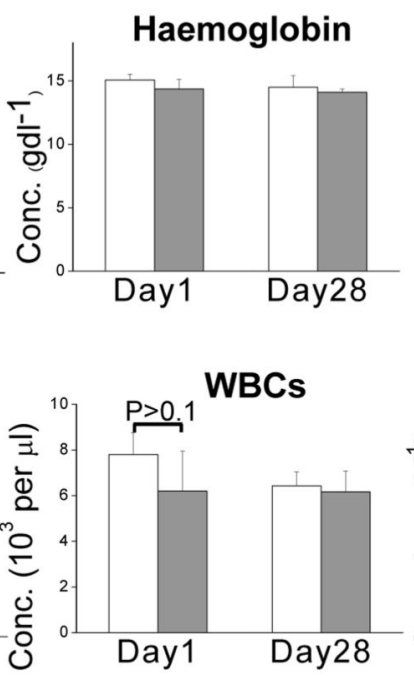
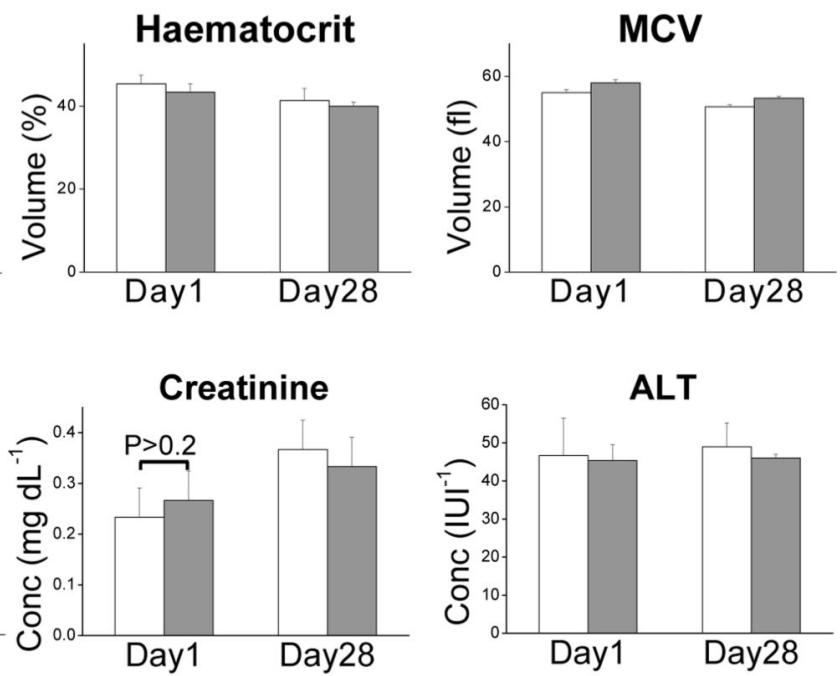

b
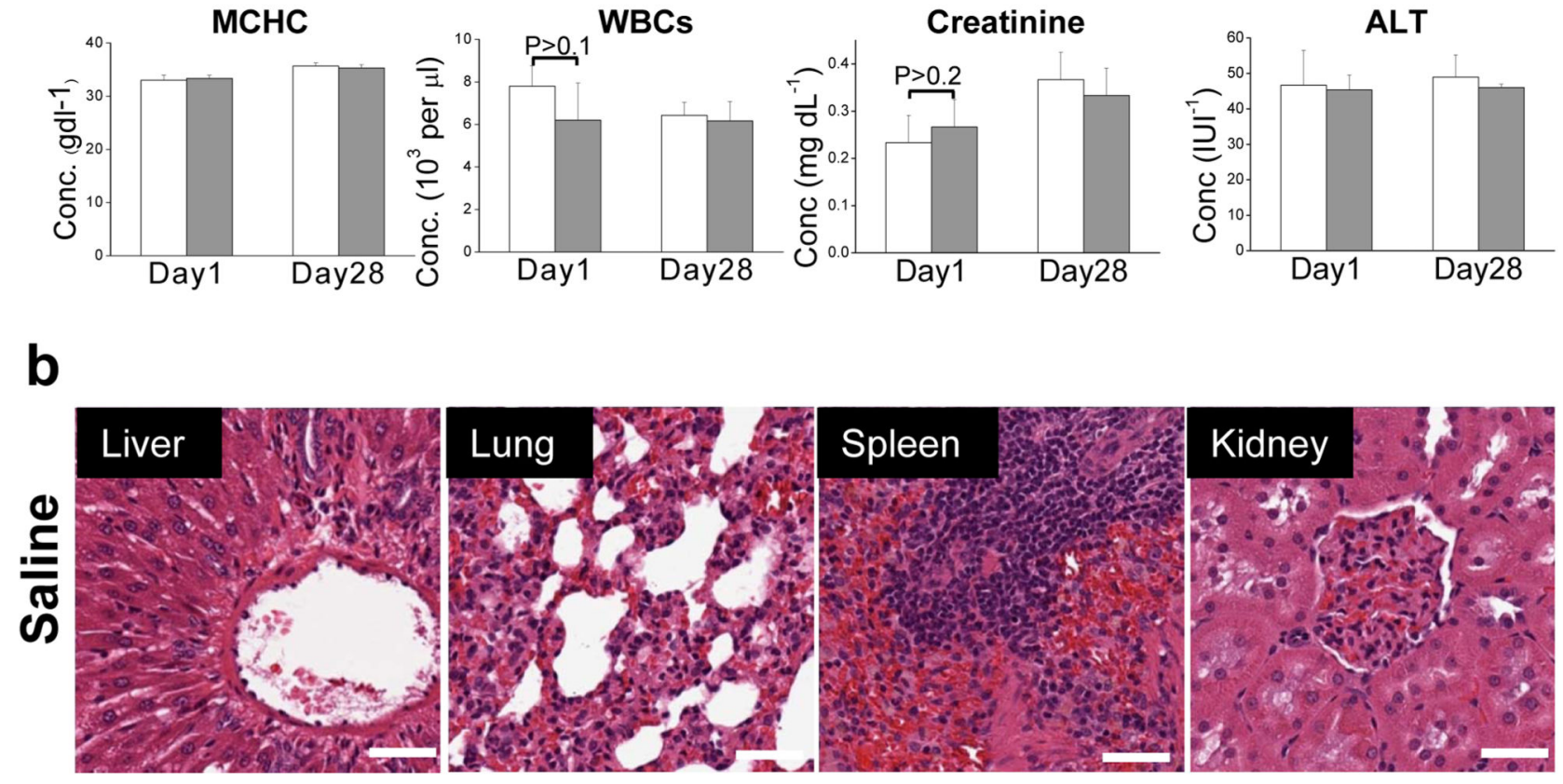

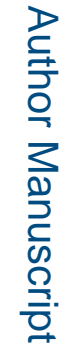
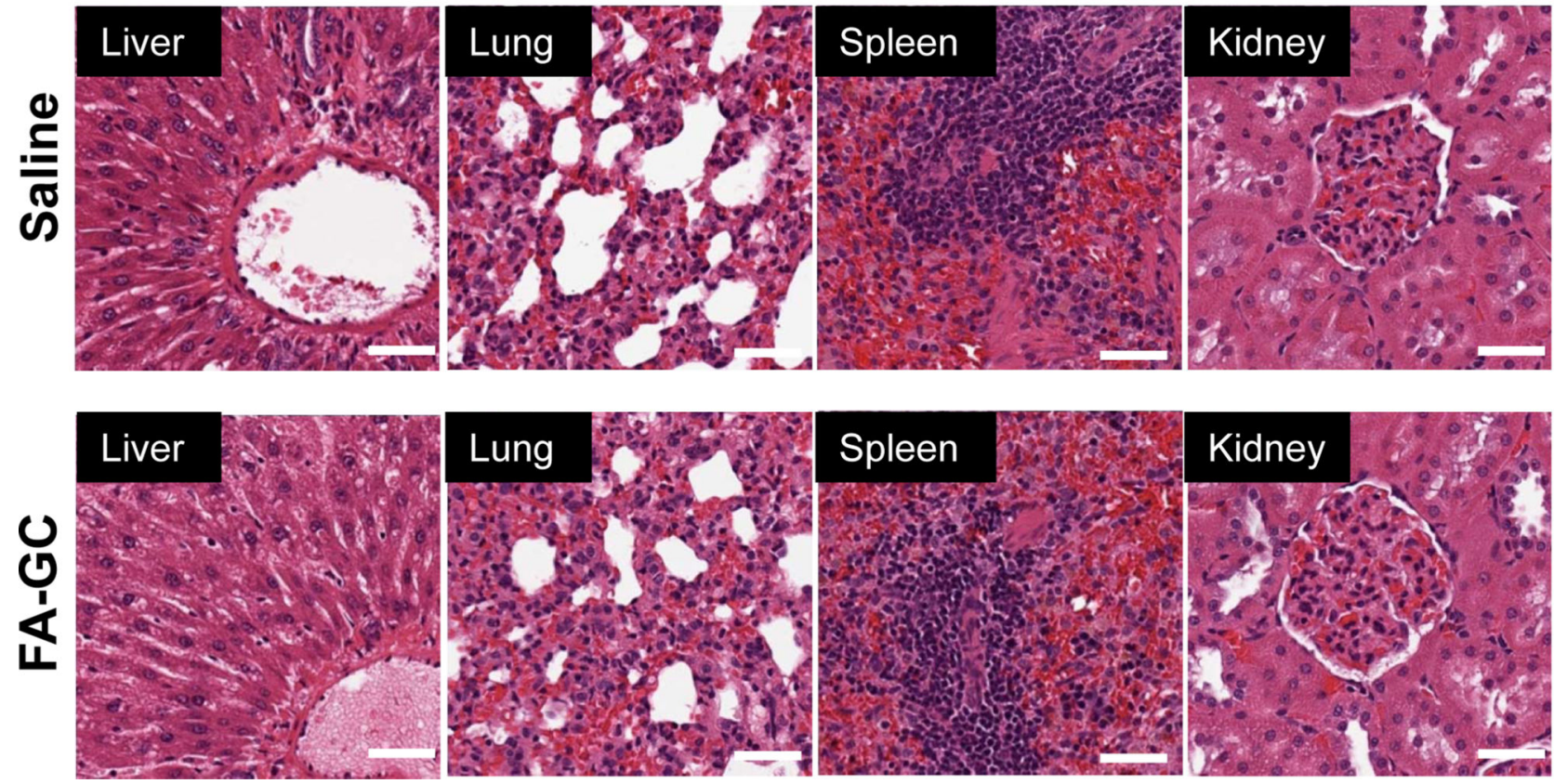

Figure 7. in vivo toxicity analysis

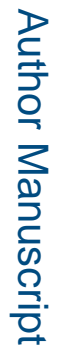

(a) Complete blood count and serum analysis of Long-Evans rats at day 1 and day 28 following injection of saline solution $(1 \mathrm{ml})$ or d FA-GC nanoparticles $(16 \mathrm{mg} / \mathrm{kg}, 1 \mathrm{ml}$ in saline). White column: saline. Gray column: FA-GC nanoparticles. (b) Histological analysis of explanted liver, lung, spleen, and kidney stained with hematoxylin and eosin. (Scale bar: $50 \mu \mathrm{m})$. 